\title{
Indian coastal ocean radar network
}

\author{
B. K. Jena*, K. S. Arunraj, V. Suseentharan, Kukadiya Tushar and T. Karthikeyan
}

As a part of the Indian Ocean Observation Network, National Institute of Ocean Technology operates and maintains a network of high frequency radar (HFR) systems along the Indian coast, known as Indian coastal ocean radar network (ICORN). It is a land-based remote sensing system capable of measuring surface currents as far as $200 \mathrm{~km}$ from the coast and waves, and wind direction nearly $100 \mathrm{~km}$ offshore. The HFR systems utilize electromagnetic waves in the 3-45 MHz frequency band and use Bragg scattering principle to deduce the oceanographic parameters. ICORN currently operates and maintains five pairs (10 sites) of long-range systems ( $5 \mathrm{MHz}$ ) which covers four states and Andaman and Nicobar Islands. These systems operate at a spatial resolution of $6 \mathrm{~km}$ and temporal resolution of one hour. Indian National Centre for Ocean Information Services at Hyderabad disseminates this data for scientific and maritime operations. The potential of HFR systems is enormous and can be employed in various facets of operational oceanography and applied research.

Keywords: HF radar, EICC, ICORN, surface currents, waves.

COASTAL oceans are subjected to complex forcing mechanisms that occur on different temporal and spatial scales. The variability associated with these turbulent motions are difficult to model and require extensive computational resources. Coastal currents of the Indian west (West India Coastal Current, WICC) and the east coasts (East India Coastal Current, EICC) reverse seasonally in response to the reversal of monsoon winds as well as the remote forcing from baroclinic waves (equatorial Kelvin and Rossby waves and coastal Kelvin waves) ${ }^{1}$. Direct current measurements are sparodic in the Arabian sea, as well as, in the Bay of Bengal (BoB). Moored Acoustic Doppler Current Profiler (ADCP) network maintained by the National Institute of Oceanography, Goa as a part of Ocean Observation Network (OON) project of the Ministry of Earth Sciences (MoES) is the only source of longterm measurement of currents along east and west coasts of India ${ }^{2,3}$. Surface current velocity measured with an ADCP contains errors due to side lobe interference and blanking zone near the ocean surface ${ }^{4}$. Advancements in remote sensing technologies have improved the ocean observation along the Indian coast. High Frequency Radar (HFR) is one such technology, which measures oceanographic parameters using electromagnetic (EM) waves from a shore based system. HFR provides valuable information on surface currents and waves in the coastal regime to understand the near shore dynamics ${ }^{5}$. The advantage of HFR system is its high resolution mapping

The authors are in the Coastal and Environmental Engineering Division, National Institute of Ocean Technology, Chennai 600 100, India.

*For correspondence. (e-mail: bkjena@niot.res.in) capability (both spatial and temporal) and near-real time data transmission. HFR observations along the Indian coast can provide an insight on the surface dynamics in the coastal zone, which in turn improves the understanding of EICC and WICC.

HFR system utilizes EM waves in the 3-45 MHz frequency band. It uses the conductivity of the ocean to transmit the modulated EM waves beyond the horizon and the sea surface acts as a diffraction grating to backscatter the signal back to the receiver. The theory of HF and VHF propagation across the rough sea was developed by Barrick ${ }^{6,7}$ and, it was Stewart $^{8}$ who proposed the use of HFR system for operational oceanography in the coastal region. HFR systems for an oceanographic purpose was first developed by Barrick $^{9}$ who called it Coastal Ocean Dynamics Applications Radar (CODAR). Similarly, Wellen Radar (WERA), another HFR system developed by Gurgel ${ }^{10}$ uses phased array antennas for current and wave measurement. WERA systems use beam-forming methods to determine the direction of arrival of backscattered echo, whereas CODAR uses directionfinding algorithm MUSIC (MUltiple SIgnal Classification) to determine the bearing of the received signal. For more information on basics of HFR mapping, please visit following websites CODAR (http://www.codar.com) and WERA (http://www.helzel.com/de/133956-WERA-OceanRadar). Approximately, 400 HFR systems are installed worldwide and are being used for wide range of applications by various agencies ${ }^{11,12}$. Integrated HFR networks are being run by various countries like India (ICORN), USA (US-IOOS), Australia (ACORN), China, Japan, Taiwan, South Korea ${ }^{13-16}$. In Europe, different countries 
are working together to materialize a Pan-European HF Radar Network ${ }^{5}$.

The potential of HFR systems has not been fully tapped and promoting this technology is a crucial element for integrated coastal zone management and development of the Indian coastal operational oceanography. This article presents an overview of the HFR operating principles, HFR network in India: its activities, data dissemination, applications of this data and steps towards the expansion of this observation network along the Indian coast.

\section{HFR - Principle of operation, data description and limitations}

The backscattering of electromagnetic waves from rough seas was first identified by Crombie ${ }^{17}$. He observed a peak in the spectral energy at half the transmitted wavelength. Later Barrick ${ }^{6,7}$ developed the theory for HF and VHF radar. Transmitted signals get scattered in all direction by random sea waves. But, the radar signal returns directly to its source only when it scatters of a wave that is exactly half the transmitted signal wavelength and it adds coherently to form a strong return of energy at a very precise wavelength - Bragg scattering principle. The backscattered signal exhibits a doppler shift from the transmitted frequency. According to the deep water linear wave theory, the returned signals are concentrated at a known position (first-order peak) in the absence of an underlying current. But, in the presence of ocean currents, an additional shift in the first-order peak is observed. This shift in frequency is deduced to get the current velocity in a radial path (towards or away from the radar). The predicted doppler shift from deep water linear wave theory in the absence of a current field is given as

$$
f_{b}= \pm \sqrt{\frac{g f_{r}}{\pi c}},
$$

where $f_{r}$ is the transmitted frequency, $g$ the acceleration due to gravity and $c$ is the speed of light. In the presence of an underlying current, the first-order peaks shift from theoretical value as

$$
\Delta f=\frac{2 V_{r} f_{r}}{c},
$$

where $V_{r}$ is the radial velocity, away from or towards the radar. Single HF radar system measures only the radial velocity (towards or away from the radar) and radials from at least two sites are required to calculate twodimensional surface current (speed and direction). Vectors are calculated using an unweighted least squares method $^{18}$ with prescribed geometric dilution of precision (GDOP); it is a function of the angle of intersection between radial velocities from pairing sites. Doppler resolution $\left(\Delta v=\lambda_{r} / 2 T=c / 2 T f_{r}\right)$ of HFR system is given by $\operatorname{Cosoli}^{19}$. Here $T$ is the time taken for collecting raw doppler spectra. The operation of EM spectrum in the HFR range is limited to the international and national regulations. Depending on the operating frequency of the HFR systems, spatial resolution of surface velocity varies from $75 \mathrm{~m}$ for a short-range system to $6 \mathrm{~km}$ for a longrange system. A long-range $(\sim 5 \mathrm{MHz})$ system can cover approximately up to $200 \mathrm{~km}$ offshore and nearly twothirds of the range alongshore; but, it also depends on the coastline orientation. For long-range HFR system collecting raw spectra in every $17 \mathrm{~min}(1024 \mathrm{~s})$ with $1 \mathrm{~Hz}$ sampling rate has a doppler resolution of $3.3 \mathrm{~cm} / \mathrm{s}$.

Ocean wave parameters are derived from the second order peak adjacent to the first-order peak in the frequency spectra by the inversion of a two-dimensional nonlinear integral equation ${ }^{20}$. The scope of the wave measurement by HFR is limited to its operating frequency. The long-range $(\sim 5 \mathrm{MHz})$ systems can only measure wave heights greater than $1.4 \mathrm{~m}$ whereas a standard range HFR system $(12 \mathrm{MHz})$ can measure wave heights greater than $0.4 \mathrm{~m}$ (ref. 20). HFR systems also provide wind direction as an output (derived from wave direction) assuming that the waves are wind induced.

Even the most sophisticated instruments suffer from unreliable measurements. HFR system is not an exception. The uncertainties associated with HFR measurements are: (a) variations of the radial current field within the radar scattering patch and over the duration of the radar measurement; (b) error from calibration (antenna pattern measurement) or from first-order line determination; (c) interferences in spectral data from power-line disturbances, ionosphere clutter, radio frequency interferences, or other environmental noises ${ }^{5}$. These uncertainties affect the spatial and temporal resolution of the data. Frequent calibration and validation exercises are carried out to minimize the discrepancies in the current and wave measurements.

\section{Indian HFR network}

Coastal and Environmental Engineering Division (CEE) of NIOT operates and maintains a network of HFR systems along the Indian coast and Andaman Islands known as Indian Coastal Ocean Radar Network (ICORN) as a part of Indian Ocean Observation Network (IOON) project of MoES. The first phase of the installation of $\mathrm{HF}$ radar systems started in 2008 and was completed by 2010. Out of 10 sites, 6 are located along the east coast of India, a pair covering Gulf of Khambhat in Gujarat and the remaining two are in Andaman Islands. Location and coverage of the HFR stations at each site is provided in (Figure 1). ICORN uses compact direction-finding (DF) systems (SeaSonde) manufactured by CODAR Ocean 
Table 1. Characteristics and operational parameters of ICORN sites

\begin{tabular}{|c|c|c|c|c|c|c|c|c|}
\hline ICORN sites & $\begin{array}{l}\text { Operating } \\
\text { frequency } \\
f_{\mathrm{em}}(\mathrm{MHz})\end{array}$ & $\begin{array}{l}\text { Band } \\
\text { width } \\
(\mathrm{KHz})\end{array}$ & $\begin{array}{c}\text { Radar } \\
\text { wavelength } \\
\lambda(\mathrm{m})\end{array}$ & $\begin{array}{c}\text { Ocean } \\
\text { wavelength } \\
\Lambda(\mathrm{m})\end{array}$ & $\begin{array}{c}\text { Ocean } \\
\text { waveperiod } \\
T(\mathrm{~S})\end{array}$ & $\begin{array}{l}\text { Maximum } \\
\quad \text { range } \\
R_{\max }(\mathrm{km})\end{array}$ & $\begin{array}{l}\text { Range } \\
\text { resolution } \\
\mathrm{d} r(\mathrm{~km})\end{array}$ & $\begin{array}{c}\text { Temporal } \\
\text { resolution } \\
T_{\text {res }}(\mathrm{h})\end{array}$ \\
\hline $\begin{array}{l}\text { KALP, CUDA, GOPA, PURI, WASI, } \\
\text { JEGRI, PTBL, HTBY }\end{array}$ & 4.4 & 25 & 68 & 34 & 4.66 & 200 & 6 & 1 \\
\hline YANM, MACH & 4.43 & 25 & 67 & 33.5 & 4.63 & 200 & 6 & 1 \\
\hline
\end{tabular}

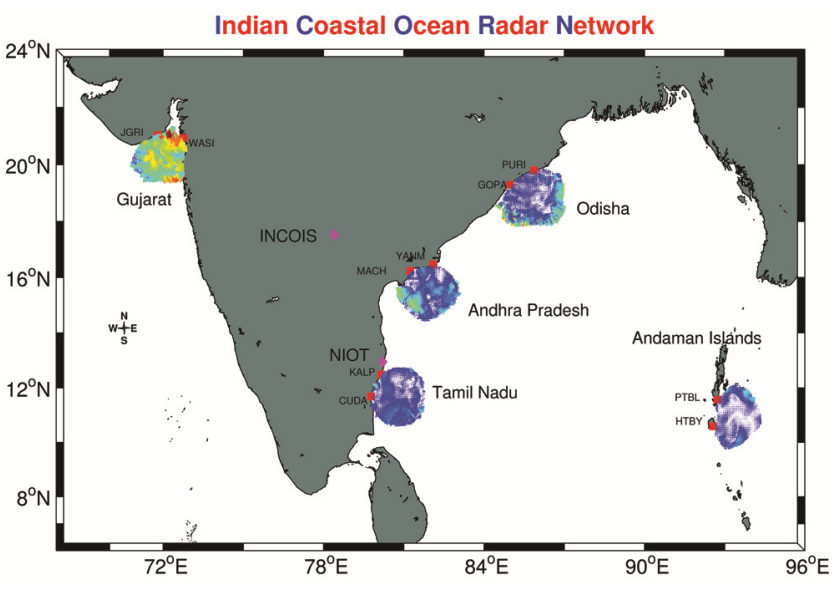

Figure 1. Indian Coastal Ocean Radar Network: The radar stations are depicted by the solid red squares and the $2 \mathrm{D}$ surface current maps are plotted at each paired sites. The central data servers at NIOT and INCOIS are marked by magenta colour diamond markers.

Sensors, USA. Sea-Sonde systems have a transmitter antenna (height $\sim 7 \mathrm{~m}$ ) and a receiver antenna (height $\sim 4 \mathrm{~m}$ ) with two magnetic dipoles (named loop 1 and loop 2) and one electric monopole. These antennas are separated by a minimum distance of one wavelength of the transmitted frequency. The SeaSonde uses pulsed Frequency Modulated Interrupted Continuous Wave (FMICW) modulation with a $50 \%$ duty cycle, and uses MUSIC algorithm for finding direction. Details of the HFR systems configurations and their necessary operational parameters are provided in Table 1.

Remote stations are named with 4 characters for their identification; usually they bear the first four letters of the local town. In Tamil Nadu (Cuddalore - CUDA, Kalpakkam - KALP), Andhra Pradesh (Machilipatanam MACH, S Yanam - YANM), Odisha (Gopalpur - GOPA, Puri - PURI), Gujarat (Wasiborsi - WASI, Jegri - JGRI), Andaman Islands (Port Blair - PTBL, Hut bay - HTBY). The radial files carry these names and corresponding timestamps for each data in the archive. The size of the radial data files are of the order of 200 Kilo bytes $(\mathrm{Kb})$ and are transferred to the central servers at NIOT and INCOIS through V-SAT/GPRS network every one hour for radial velocity, $30 \mathrm{~min}$ for waves and every $10 \mathrm{~min}$ for the site diagnostic files. Diagnostic files help in analysing the current working condition of various components of the system and aid in the quality assessment/ quality control (QA/QC) procedures of the data. ICORN follows standard protocols for operation, maintenance, data acquisition and QA/QC. Antenna calibration also known as Antenna Pattern Measurement (APM) is carried out once in six months or whenever a hardware is changed. APM is also carried out whenever a new construction has come up near the radar site. Validation of the HFR derived currents is a major task before dissemination. An array of drifters are employed along the coast to validate the HFR surface currents by comparing drifter trajectory with HFR data derived trajectory. This data undergoes a rigorous data processing procedure adhering to the international protocols of processing and calibration. Strategy of ICORN is to fully curate the data in a national data archive at the Indian National Centre for Ocean Information Services (INCOIS) at Hyderabad and disseminate the data for scientific and maritime operations. Flow chart showing the data transmission in ICORN is provided in Figure 2. The primary product of HFR systems is the two-dimensional surface current; availability of wave and wind parameters are subjected to the prevailing sea condition and operating frequency (discussed previously). Percentage of availability of surface current data in ICORN from 2008 to 2017 is provided in Table 2. Lower percentages of data at certain sites are either due to natural disasters or technical glitches in the equipments. ICORN provides data to the researchers on a request basis through INCOIS. Presently the main users of this data are academia (Coastal Zone Management Studies, Anna University, Andhra University, Annamalai University - Chidambaram, Indian Institutes of Technology-Chennai, Mumbai, Khargapur and Bhubaneswar) and research institutes (NIO, Goa, IGCAR, Kalpakkam, SAC, Ahmedabad, NODPAC, Kochi, Visakhapatnam, NPOL, Kochi).

\section{Applications of HFR networks}

HFR network gives us an edge over conventional single point current measurements by providing two-dimensional surface circulation in near real time. These high resolution data help in studying the dynamics of the coastal ocean, the interaction between physical and biological parameters in the ocean, transport mechanisms between the estuary and coastal waters. Assimilation of data from HFR systems improves the ocean circulation models 
GENERAL ARTICLES

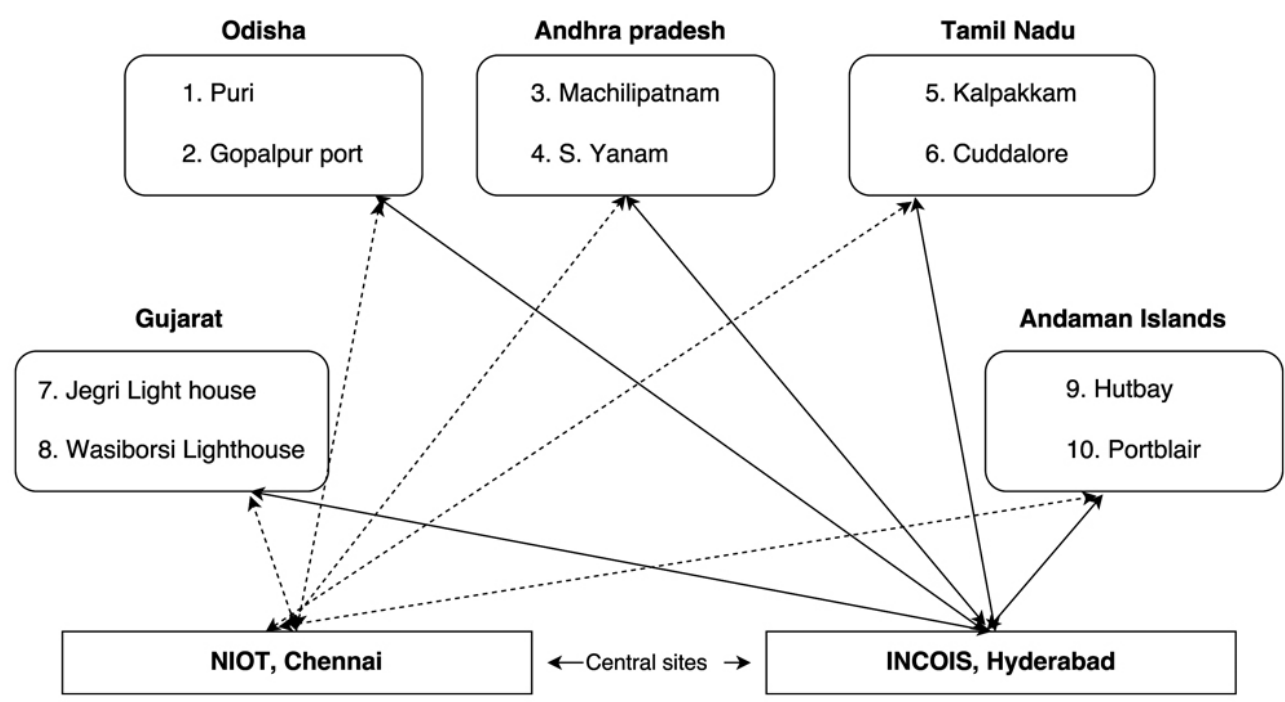

Figure 2. Flow chart of the data management system in ICORN. Data is transferred from remote sites to the central stations at INCOIS, Hyderabad and NIOT, Chennai in near real time through V-SAT/GPRS network.

Table 2. Percentage availability of current data from ICORN at different sites from 2008 to 2017

\begin{tabular}{|c|c|c|c|c|c|c|c|c|c|c|c|}
\hline State & Site Year & $\begin{array}{l}2008 \\
(\%) \\
\end{array}$ & $\begin{array}{l}2009 \\
(\%) \\
\end{array}$ & $\begin{array}{l}2010 \\
(\%)\end{array}$ & $\begin{array}{l}2011 \\
(\%)\end{array}$ & $\begin{array}{l}2012 \\
(\%) \\
\end{array}$ & $\begin{array}{l}2013 \\
(\%)\end{array}$ & $\begin{array}{l}2014 \\
(\%) \\
\end{array}$ & $\begin{array}{l}2015 \\
(\%) \\
\end{array}$ & $\begin{array}{l}2016 \\
(\%) \\
\end{array}$ & $\begin{array}{l}2017 \\
(\%) \\
\end{array}$ \\
\hline \multirow{3}{*}{ Tamil Nadu } & $\operatorname{CUDA}\left(11.68^{\circ} \mathrm{N}, 79.77^{\circ} \mathrm{E}\right)$ & 12 & 84 & 61 & 90 & 24 & 56 & 96 & 94 & 97 & 95 \\
\hline & $\operatorname{KALP}\left(12.49^{\circ} \mathrm{N}, 80.15^{\circ} \mathrm{E}\right)$ & 53 & 91 & 99 & 99 & 95 & 52 & 97 & 96 & 96 & 98 \\
\hline & Combined & 11 & 76 & 61 & 84 & 24 & 48 & 93 & 90 & 93 & 92 \\
\hline \multirow{3}{*}{ Andhra Pradesh } & $\mathrm{MACH}\left(16.24^{\circ} \mathrm{N}, 81.24^{\circ} \mathrm{E}\right)$ & 10 & 59 & 82 & 90 & 68 & 68 & 85 & 67 & 98 & 88 \\
\hline & YANM $\left(16.48^{\circ} \mathrm{N}, 82.10^{\circ} \mathrm{E}\right)$ & 2 & 10 & 45 & 64 & 66 & 25 & 81 & 78 & 83 & 86 \\
\hline & Combined & 2 & 8 & 41 & 54 & 43 & 16 & 69 & 59 & 81 & 79 \\
\hline \multirow{3}{*}{ Gujarat } & WASI $\left(20.93^{\circ} \mathrm{N}, 72.76^{\circ} \mathrm{E}\right)$ & NA & 35 & 72 & 76 & 80 & 93 & 71 & 35 & 62 & 8 \\
\hline & $\operatorname{JGRI}\left(21.04^{\circ} \mathrm{N}, 71.81^{\circ} \mathrm{E}\right)$ & NA & 55 & 89 & 83 & 78 & 43 & 83 & 82 & 65 & 61 \\
\hline & Combined & NA & 29 & 65 & 65 & 66 & 41 & 57 & 33 & 58 & 7 \\
\hline \multirow{3}{*}{ Odisha } & $\operatorname{GOPA}\left(19.30^{\circ} \mathrm{N}, 84.97^{\circ} \mathrm{E}\right)$ & NA & 15 & 45 & 76 & 37 & 49 & 2 & 97 & 87 & 93 \\
\hline & $\operatorname{PURI}\left(19.81^{\circ} \mathrm{N}, 85.86^{\circ} \mathrm{E}\right)$ & NA & 7 & 73 & 87 & 23 & 26 & 73 & 95 & 88 & 96 \\
\hline & Combined & NA & 7 & 44 & 67 & 16 & 22 & 2 & 93 & 82 & 90 \\
\hline \multirow{3}{*}{ Andaman Islands } & PTBL $\left(11.57^{\circ} \mathrm{N}, 92.74^{\circ} \mathrm{E}\right)$ & $\mathrm{NA}$ & $\mathrm{NA}$ & 47 & 74 & 60 & 62 & 63 & 97 & 93 & 98 \\
\hline & $\operatorname{HTBY}\left(10.59^{\circ} \mathrm{N}, 92.56^{\circ} \mathrm{E}\right)$ & $\mathrm{NA}$ & $\mathrm{NA}$ & 57 & 89 & 81 & 47 & 93 & 52 & 88 & 95 \\
\hline & Combined & NA & NA & 42 & 67 & 48 & 36 & 60 & 51 & 82 & 93 \\
\hline
\end{tabular}

$$
\geq 70 \% \quad \geq 50<70 \% \quad<50 \% \quad \text { Not installed }
$$

and their validation. Uses of HFR systems can be further extended to monitor the marine resources, vessel traffic near the coast and tracking marine pollution. Use of HFR data in studying the movement of larvae can bolster the fisheries and related industries. The data from the HFR system can be used as an input for weather forecast modelling and aid in tidal and storm measurements. Apart from these applications, the data can also be used for algorithm development to enhance the utility of the HFR systems. Portable HFR systems can be deployed at any location to support disaster mitigation, search and rescue operations, oil-spill monitoring/tracking, warning to the surfers and rip current advisories for the public ${ }^{5,12}$.

\section{Outputs from the ICORN}

HFR networks are widely used to study the coastal ocean dynamics across the world. Researchers from various facets of engineering and science fields use the data from ICORN to study the coastal processes along the Indian coast. HFR systems were able to capture the intrinsic features of EICC on various spatial and temporal scales. These eddy resolving observations were able to describe the seasonal reversal of EICC and associated variability better than ever before. The poleward (February) and equatorward (October) shift of EICC is given in the monthly averaged currents from ICORN (Figure 3). 

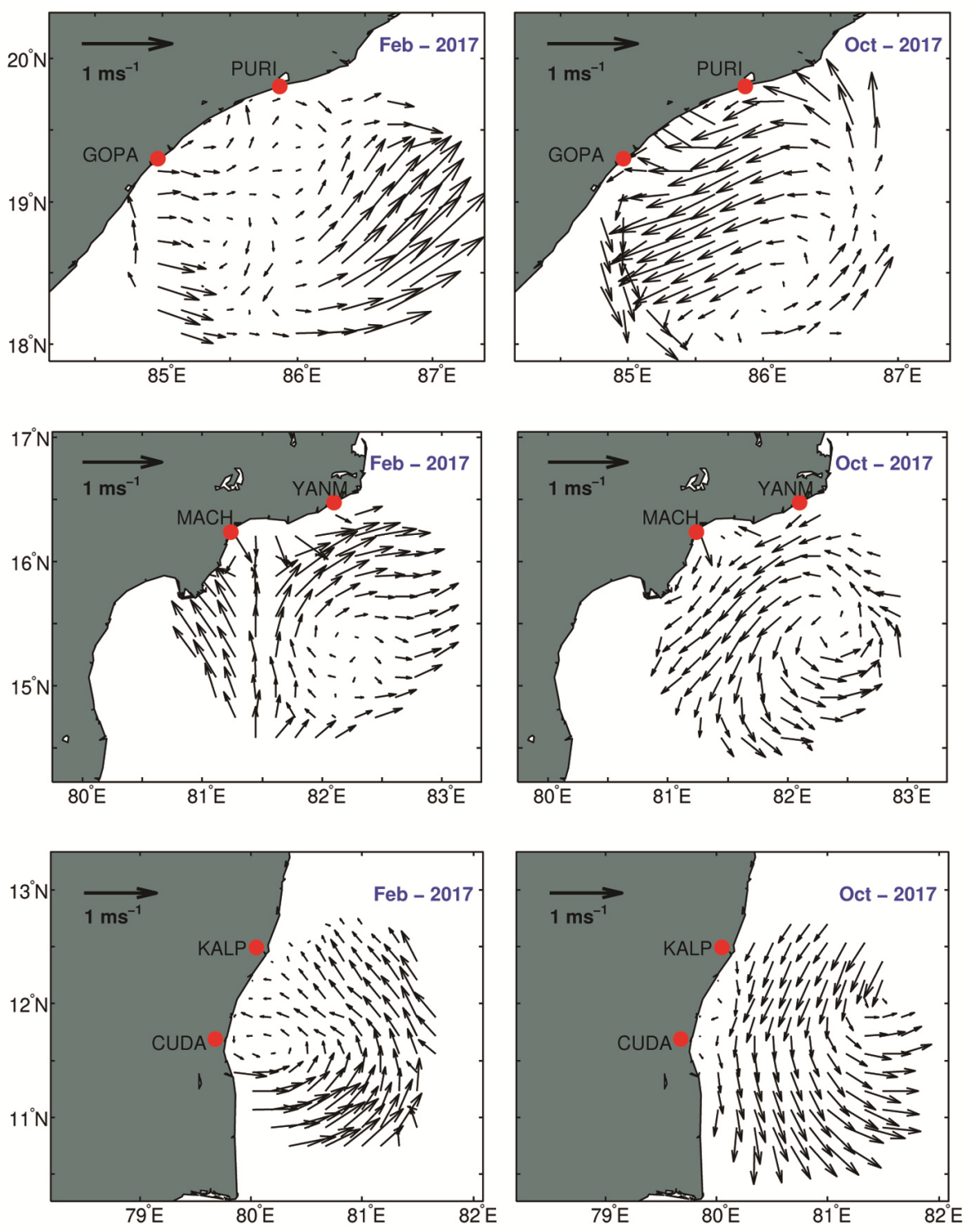

Figure 3. Surface current maps showing the seasonal reversal of EICC from HFR station at Odisha, Andhra Pradesh and Tamil Nadu coast respectively between February and October 2017.

Meso-scale and sub-meso-scale eddies associated with the EICC and their impact on biophysical properties of the coastal oceans and the spatiotemporal variation in surface currents during the cyclonic event were studied with this data ${ }^{21-24}$. Surface current pattern from HFR at the Andaman islands showing the jet flows between islands during the Phailin cyclone ${ }^{13}$ is shown in Figure $4 a$. As far as ICORN is concerned, it was able to capture all the high wave activities during the cyclonic events which came under its coverage area ${ }^{13}$. Typical wind and wave measurements from HFR in KALP at a distance of $18 \mathrm{~km}$ from the coast is given in Figure $4 b$. The Gulf of Khambat in Gujarat coast is known for its tidal ranges and the currents. Semi-diurnal and fortnight harmonics of the tide strongly influence the surface currents here. The upper panel in Figure $4 c$ shows the stick plots of the surface current obtained from a grid point in HFR domain and the lower panel shows the stick plots merged with modelled tide for two days at the same grid. Tide data has been scaled down to one-fourth of its original value for better clarity. Since detailed descriptions are beyond the scope of this article, we have presented only some of the outputs from the ICORN.

\section{Prospects for future development - ICORN}

ICORN currently runs with 10 HFR systems which cover approximately $10 \%$ of the total coastline $(\sim 7500 \mathrm{~km})$. As a part of the effort of MoES to improve the Ocean Observation Network, ICORN is also trying to spread its wings all along the Indian coast in a phased manner with different 

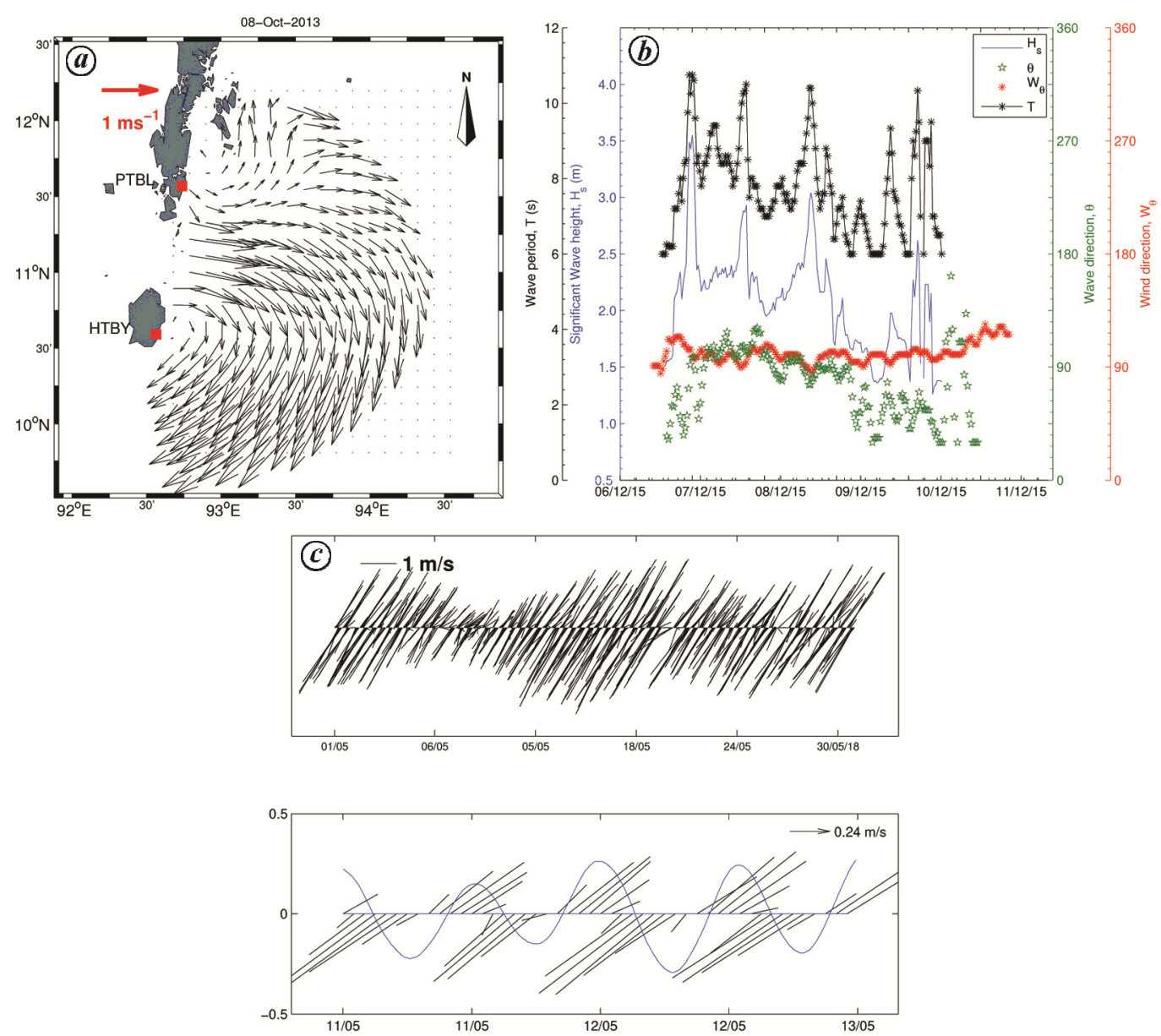

Figure 4. $\boldsymbol{a}$, Circulation pattern from HFR at Andaman Island during Phailin cyclone. $\boldsymbol{b}$, Wave and wind parameters measured with HFR station at KALP for the third range cell (18 km offshore) in December 2015. c, Stick plot of one-month surface current data from a grid point in HFR coverage at Gujarat coast is in the upper panel and two days of the same data overlapped with tides during that period is provided in the lower panel. The tides are scaled down to match with surface current data from HFR.

configurations of HFR system depending on the project requirement and topographical constraints. With the increase in the number of HFR systems, the allocation of frequency bandwidth needs changes and requires collaborative work between different ministries within the country and other countries as well ${ }^{15}$. A more robust data management system should be placed in central stations to archive and distribute the data to the research community more efficiently. Inclusion of ICORN data in the ocean state and weather forecasting models of INCOIS and Indian meteorological department would improve the disaster management programmes of the MoES along the east coast of India. The use of these systems can be extended further for search and rescue operation by assimilating observed data into models and narrowing down the search area for the coast guards. Improved particle tracking algorithms can be implemented on these data sets for oil spill monitoring. Helping port and harbour authority in managing vessel traffic in ports is one of the emerging prospects of these systems. Timely inclusion of HFR in coastal oceanography will enhance the applied research in numerical model validation, advancements in signal processing techniques, recreational aspects and maritime safety.

1. Amol, P. et al., Observational evidence from direct current measurements for propagation of remotely forced waves on the shelf of the west coast of India. J. Geophys. Res. Oceans, 2012, 117(C05017), 1-15; doi:10.1029/2011JC007606.

2. Amol, P. et al., Observed intraseasonal and seasonal variability of the West India coastal current on the continental slope. J. Earth Syst. Sci., 2014, 123(5), 1045-1074.

3. Mukherjee, A. et al., Observed seasonal and intraseasonal variability of the east India coastal current on the continental slope. $J$. Earth Syst. Sci., 2014, 123(6), 1197-1232.

4. Parks, A. B., Shay, L. K., Johns, W. E., Martinez-Pedraja, J. and Gurgel, K. W., HF radar observations of small-scale surface current variability in the straits of Florida. J. Geophys. Res. Oceans, 2009, 114(8), 1-17; doi:10.1029/2008JC005025.

5. Rubio, A. et al., HF radar activity in European coastal seas: next steps towards a pan-European HF radar network. Front Mar. Sci., 2017, 4(8), 1-20.

6. Barrick, D. E., Theory of HF and VHF propagation across the rough sea, 1 , the effective surface impedance for a slightly rough 
highly conducting medium at grazing incidence. Radio Sci., 1971, 6(5), 517-526.

7. Barrick, D. E., Theory of HF and VHF propagation across the rough sea, 2, application to HF and VHF propagation above the sea. Radio Sci., 1971, 6(5), 527-533.

8. Stewart, R. H. and Joy, J. W., HF radio measurements of ocean surface currents. Deep Sea Res., 1974, 21, 1039-1049.

9. Barrick, D. E., Evans, M. W. and Weber, B. L., Ocean surface currents mapped by radar. Science, 1977, 198(4313), 138-144.

10. Gurgel, K. W., Antonischki, G., Essen, H. H. and Schlick, T., Wellen Radar (WERA): A new ground-wave HF radar for ocean remote sensing. Coast Eng., 1999, 37, 219-234.

11. Roarty, H., Hazard, L. and Fanjul, E., Growing network of radar systems monitors ocean surface currents. Eos (Washington DC), 2016, 97; doi:10.1029/2016EO049243.

12. Paduan, J. D. and Washburn, L., High-frequency radar observations of ocean surface currents. Annu. Rev. Mar. Sci., 2013, 5, 115136; http://www.ncbi.nlm.nih.gov/pubmed/22809196.doi:10.1146/ annurev-marine-121211-172315.

13. John, M., Jena, B. K. and Sivakholundu, K. M., Surface current and wave measurement during cyclone Phailin by high frequency radars along the Indian coast. Curr. Sci., 2015, 108(3), 405-409.

14. Harlan, J., Terrill, E., Hazard, L., Otero, M. and Roarty, H., The integrated ocean observing system HF radar network. Ocean MTS/IEEE Washington, 2015.

15. Wyatt, L. R., Coastal Ocean Observing Systems, 2015; ISBN9780128020227.

16. Fujii, S. et al., An overview of developments and applications of oceanographic radar networks in Asia and Oceania countries. Ocean Sci. J., 2013, 48(1), 69-97; doi:10.1007/s12601-013-0007-0.

17. Crombie, D. D., Doppler spectrum of Sea Echoat $13.56 \mathrm{Mc} . / \mathrm{s}$. Nature, 1955, 175(4459), 681-682.

18. Lipa, B. and Barrick, D., Least-squares methods for the extraction of surface currents from CODAR crossed-loop data: Application at ARSLOE. IEEE J. Ocean Eng., 1983, 8.

19. Cosoli, S., Bolzon, G. and Mazzoldi, A., A real-time and offline quality control methodology for seasonde high-frequency radar currents. J. Atmos. Ocean Technol., 2012, 29(9), 1313-1328; doi:10.1175/JTECH-D-11-00217.1.

20. Lipa, B., Derivation of directional ocean wave spectra by integral inversion of the second order radar echoes. Radio Sci., 1977, 12(3), 425-434.

21. Arunraj, K. S., Suseentharan, V. and Jena, B. K., Observations of small-scale variability in surface currents along the East coast of India from HF radar Network. In IRAD2017, Indian Inst. Technol. Kharagpur, 2017.

22. Samiran, M., Sourav, S., Arunraj, K. S. and Jena, B. K., Submesoscale circulation features along Andhra coast: observations from HF radar. In OSICON17, NCESS, Thiruvananthapuram, 2017.

23. Arunraj, K. S., Jena, B. K., Suseentharan, V., Tushar, K. and Ramanamurthy, M. V., Variation in surface current along Tamil Nadu coast during NADA and VARDAH cyclones from HF Radar observations. In: OSICON17, NCESS, Thiruvananthapuram, 2017.

24. Arunraj, K., Jena, B. K., Suseentharan, V. and Rajkumar, J., Variability in eddy distribution associated with East India Coastal Current from high-frequency radar observations along southeast coast of India. J. Geophys. Res. Ocean, 2018, 123; https://doi.org/ 10.1029/2018JC014041.

ACKNOWLEDGEMENTS. We thank The Director, National Institute of Ocean Technology, Chennai for guidance and encouragement, and Ministry of Earth Sciences, Government of India, for providing funds for the establishment and maintenance of the Indian Coastal Ocean Radar Network along the Indian coast. We also acknowledge V. Vishal, Rajnish Antala, Manu P. John for their contribution in setting up the HFR stations in the initial stages of ICORN. We also acknowledge staff and colleagues in NIOT who have been an integral part of the ICORN.

Received 12 January 2018; revised accepted 13 November 2018

doi: $10.18520 / \mathrm{cs} / \mathrm{v} 116 / \mathrm{i} 3 / 372-378$ 